\title{
Subsídios para uma Leitura Desenvolvimental do Processo de Envelhecimento
}

\section{Conceptualizing a Developmental Approach of the Process of Aging}

\author{
António M. Fonseca* \\ Universidade Católica Portuguesa, Porto, Portugal
}

\begin{abstract}
Resumo
Apresenta-se um conjunto de perspectivas teóricas que encaram o desenvolvimento psicológico como uma sucessão coerente de mudanças sistemáticas e organizadas ao nível do funcionamento e do comportamento individuais, implicando uma adaptação constante dos indivíduos face a transformações ocorridas a nível interno e externo. Inspiradas por uma compreensão contextualista do desenvolvimento, comparam-se os principais aspectos de quatro teorias que procuram explicar o modo como o desenvolvimento se faz no decurso da vida humana: abordagem ecológica, contextualismo desenvolvimental, teoria da acção e do controle, perspectiva desenvolvimental do ciclo de vida. Algumas implicações dos aspectos comuns a estas teorias são finalmente concretizadas em termos do estudo do processo de envelhecimento, salientando a importância cada vez maior de que se reveste o estudo das diferenças inter-individuais em tal processo a partir da análise de percursos individuais de desenvolvimento.

Palavras-chave: Desenvolvimento; ciclo de vida; envelhecimento.

Abstract

Some theoretical approaches that look into human development as a coherent movement of systematic and organized changes in individual functioning and behavior are presented. These changes will demand a constant individual adaptation coping with transformations occurring in internal and external levels. Inspired by a contextualist paradigm of human development, the main aspects of four theories that try to explain the way how development occurs throughout human life are compared: ecological approach, developmental contextualism, theory of action and control, life-span developmental perspective. Some implications of common features of these theories are applied in what concerns the study of the process of aging, focusing the growing importance of the study of inter-individual differences in such process from the analysis of individual developmental pathways.

Keywords: Development; life-span; aging.
\end{abstract}

Desde o início do século XX que o estudo do desenvolvimento de crianças e adolescentes, primeiro, e de adultos e idosos, mais tarde, constituiu matéria suficientemente vasta para que, em poucas dezenas de anos, se tenha alterado substancialmente o modo como encaramos o desenvolvimento psicológico do ser humano. Assim, se durante a primeira metade do século XX predominaram concepções que restringiam o desenvolvimento ora à sequência crescimento-estabilidade-declínio, ora aos períodos da infância e da adolescência, ao longo da segunda metade do século foram emergindo concepções de natureza multidisciplinar que reflectiam conceitos diferenciados de desenvolvimento.

$\mathrm{O}$ alargamento do enfoque da psicologia do desenvolvimento permitiu igualmente reconhecer que o desenvolvimento não se limita à infância e adolescência mas decorre ao longo de todo o ciclo de vida do ser humano, e que, por

\footnotetext{
* Endereço para correspondência: Rua Diogo Botelho, 1327, 4169-005. Porto, Portugal. Fone: + 351.22.6196200; Fax: + 351.22.6196291. E-mail: afonseca@porto.ucp.pt
}

outro lado, não há só um caminho mas sim múltiplos caminhos possíveis de desenvolvimento, os quais se acentuam progressivamente com o avanço da idade. À medida que as pessoas envelhecem, os seus percursos de vida vão-se diferenciando cada vez mais uns dos outros, quer devido ao cruzamento de variáveis de ordem biológica e cultural, quer devido à influência exercida por toda uma série de acontecimentos de vida que vão marcando os seus comportamentos e as suas personalidades (Fonseca, 2005).

Num sentido amplo, tal como hoje é entendido pela generalidade de autores e de correntes, o desenvolvimento supõe a ocorrência de mudanças ao nível do funcionamento e do comportamento individuais. Partindo deste consenso, que poderíamos designar por "mínimo consenso comum", convém salientar, porém, que as mudanças que caracterizam o desenvolvimento humano necessitam de obedecer a um conjunto de características para que sejam consideradas $m u$ danças desenvolvimentais, sendo diversas a este respeito as perspectivas de diferentes autores (Quadro 1). 


\begin{tabular}{|c|c|c|}
\hline $\begin{array}{l}\text { Clarke-Stewart, Perlmutter } \\
\text { \& Friedman (1988) }\end{array}$ & Hoffman, Paris \& Hall (1994) & Overton(2003) \\
\hline $\begin{array}{l}\text { Desenvolvimento está intimamente } \\
\text { ligado à ocorrência de mudanças de } \\
\text { uma forma: } \\
\text { - sistemática (não aleatória), } \\
\text { - permanente (não temporária), } \\
\text { - progressiva (não regressiva), } \\
\text { - estável (não flutuante), } \\
\text { - que ocorre ao longo de um certo } \\
\text { período de tempo na vida de uma } \\
\text { pessoa (não apenas numa hora), } \\
\text { - relacionada com a idade e com a } \\
\text { experiência acumulada no decurso } \\
\text { da vida. }\end{array}$ & $\begin{array}{l}\text { Mudança desenvolvimental assume-se } \\
\text { como: } \\
\text { - contínua (desenvolvimento ocorre ao } \\
\text { longo de toda a vida, em qualquer } \\
\text { período), } \\
\text { - cumulativa (desenvolvimento } \\
\text { constrói-se a partir de bases prévias), } \\
\text { - direccionada (no sentido de uma cada } \\
\text { vez maior complexidade), } \\
\text { - diferenciadora (ao longo da vida as } \\
\text { distinções entre as pessoas tendem a } \\
\text { acentuar-se), } \\
\text { - organizada (competências decorrentes } \\
\text { das mudanças são integradas no } \\
\text { funcionamento individual de forma } \\
\text { coordenada entre si), } \\
\text { - holística (todos os aspectos do } \\
\text { desenvolvimento dependem uns dos } \\
\text { outros, interagindo mutuamente). }\end{array}$ & $\begin{array}{l}\text { Definição de desenvolvimento passa } \\
\text { pelo reconhecimento de dois tipos de } \\
\text { mudança: } \\
\text { - mudança ligada à transformação (na } \\
\text { forma, organização, ou estrutura de } \\
\text { qualquer sistema, que adquire um } \\
\text { carácter qualitativo e traduz uma } \\
\text { descontinuidade desenvolvimental, não } \\
\text { se reduzindoà “adição de comportamentos”), } \\
\text {-mudança ligadaà variação(grau ou extensão } \\
\text { em que uma determinada ocorrência } \\
\text { varia relativamente a uma norma ou a } \\
\text { uma média, configurando uma mudança } \\
\text { quantitativa e contínua). }\end{array}$ \\
\hline
\end{tabular}

Quadro 1. O que é desenvolver-se? Análise comparativa.

Partindo do princípio, então, que o desenvolvimento supõe a ocorrência de mudanças, o que origina as mudanças, logo, o que causa o desenvolvimento? Os investigadores interessados no estudo das causas do desenvolvimento humano frequentemente oscilaram entre posições extremas, situando o desenvolvimento ora como um produto de forças internas e inatas ("nature"), ora como um produto de forças externas e ambientais (“nurturê). Esta visão dicotómica, hoje no essencial ultrapassada (Overton, 2006), foi sendo progressivamente substituída por perspectivas em que o desenvolvimento é visto como interactivo, marcado por continuidades e descontinuidades, sujeito a múltiplas forças internas e externas que, em conjunto, criam uma variedade imensa de trajectórias desenvolvimentais (Lerner \& Walls, 1999).

Os psicólogos do desenvolvimento colocam hoje questões mais subtis, que vão muito para além da controvérsia “inato versus adquirido", procurando determinar as condições por meio das quais forças internas e externas trabalham juntas para produzir o desenvolvimento individual, qual o papel da pessoa nesse desenvolvimento e quais os mecanismos inerentes aos próprios processos de desenvolvimento, ou seja, como ocorrem as transições entre os diversos níveis de organização desenvolvimental e como poderemos inferir daí as diferenças que se constatam entre pessoas aparentemente sujeitas às mesmas influências. Com efeito, os psicólogos estão hoje particularmente motivados em explicar o desenvolvimento humano (isto é, a especificar os antecedentes desse desenvolvimento) e não tanto ou não apenas em descrever o desenvolvimento (através de comportamentos ou de imagens representativas das mudanças que lhe estão inerentes), especificando as condições que estão na base da continuidade e da descontinuidade desse mesmo desenvolvimento e colocando no mesmo plano de importância “o que” muda/varia e "o tipo" de mudança/variação que é verificado.

Nos últimos anos, o conceito de desenvolvimento tem vindo a evoluir no sentido de conferir uma atenção cada vez maior às perspectivas que defendem o papel activo do indivíduo na construção do seu próprio desenvolvimento, quer influenciando-o directamente (por exemplo, pela realização de escolhas), quer fazendo-o de forma indirecta, ao criar ou mudar os contextos onde esse desenvolvimento se processa. Uma visão desta natureza leva a encarar o ser humano como um sistema altamente complexo, onde se interligam dimensões de ordem biológica, cognitiva, emocional, relacional e social, um sistema que apesar de sujeito a uma evolução regular e progressiva não está confinado a uma meta desenvolvimental pré-determinada.

No quadro de uma perspectiva contemporânea de compreensão dos factores implicados no desenvolvimento humano, Lerner, Easterbrooks e Mistry (2003) sinalizam a importância do contributo de uma série de autores na consolidação de um conjunto de princípios teóricos e empíricos que sustentam hoje uma visão do desenvolvimento baseada num sistema de relações entre a pessoa e o contexto ao longo do ciclo de vida, enfatizando mais do que nunca o papel da interacção dinâmica e recíproca entre variáveis muito diversas na construção desse desenvolvimento. Entre esses autores contam-se Bronfenbrenner, Baltes, Brandstadter, Magnusson e Lerner, todos eles sublinhando “uma ênfase comum nas relações entre a pessoa e o contexto e na necessidade de enquadrar o estudo do desenvolvimento humano nos cenários reais da existência humana" (Lerner, Easterbrooks \& Mistry, p. 3). 
No essencial, o conjunto de investigadores atrás mencionados têm vindo a defender uma visão do desenvolvimento humano caracterizada: (a) por modelos integrados que sintetizam perspectivas defensoras de influências biológicas e ecológicas sobre o desenvolvimento humano; (b) pelo uso de uma vasta gama de metodologias qualitativas e quantitativas, tendo em vista a obtenção de conhecimento empírico e teórico acerca de tais influências bio-ecológicas; (c) por uma valorização crescente da importância das influências históricas, sociais e culturais nas trajectóricas individuais de desenvolvimento no decurso dos respectivos ciclos de vida; (d) pela procura de pontos de convergência entre a formulação e a aplicação da ciência desenvolvimental (Bornstein \& Lamb, 2005; Lerner, 2006).

Para Lerner, Easterbrooks e Mistry (2003), estas quatro áreas de delimitação do estudo do desenvolvimento humano mostram bem como a força da ciência desenvolvimental actual reside no seu carácter integrador. A ciência desenvolvimental contemporânea não é limitada pelo estabelecimento de associações rígidas entre a pessoa e o seu comportamento nem pela predominância de visões de cariz unidimensional acerca do funcionamento individual (por exemplo, a pessoa vista exclusivamente do ponto de vista das cognições ou das emoções):

Hoje, a pessoa em desenvolvimento não é nem biologizada, nem psicologizada, nem sociologizada. Pelo contrário, o indivíduo é sistemizado, ou seja, o seu desenvolvimento é conceptualizado e estudado tendo em conta a sua integração numa matriz de variáveis que derivam de múltiplos sistemas de organização (Lerner, Easterbrooks \& Mistry, 2003).

\section{Contextualismo: A Interacção Organismo-Ambiente}

O movimento de aproximação entre as ciências naturais e as ciências sociais implicou uma natural diluição das dicotomias tradicionais no estudo do desenvolvimento humano (inato versus adquirido, observação versus interpretação, teoria versus dados empíricos, etc.), dando lugar à consideração de propostas integradoras e convergentes. Para Overton (2006), este movimento concretizou-se através da ocorrência de três passos conceptuais que criaram condições para a emergência e consolidação do paradigma contextualista: (a) substituição de formas de interpretação reducionistas por formas de interpretação de natureza relacional, que alternam momentos de análise com momentos de síntese; (b) substituição da pesquisa de relações de causalidade pela procura de influências, condições ou acções associadas à verificação de mudanças; (c) substituição do uso de modalidades de interpretação de tipo indutivo e dedutivo por modalidades de interpretação fundadas essencialmente na produção de inferências, tidas como "a melhor explicação".

Desta transição resultou que o inquérito psicológico em geral e a pesquisa desenvolvimental em particular, passaram a estar regulados por um conjunto de métodos e conceptualizações inspirados em dimensões relativas à biologia, à cultura e à pessoa, conforme anteriormente consideradas. Com efeito, foi esta mudança de olhar epistemológico que permitiu que o desenvolvimento tenha adquirido simultaneamente uma expressão "corporizada" (ou “organísmica”) e "contextualizada”, e que factores como a intencionalidade, a experiência, a realização de escolhas, ou a atribuição de sentido, sejam hoje considerados como mecanismos desenvolvimentais "centrados na pessoa" de elevado significado psicológico.

Segundo Dowd (1990), o paradigma contextualista alicerça-se essencialmente em dois princípios fundamentais: (a) reciprocidade de relações entre o organismo e o meio, com o organismo a ser considerado um agente activo na determinação do seu desenvolvimento e o meio a ser considerado uma necessidade para a ocorrência da progressão desenvolvimental, susceptível não só de estimular mas também de inibir essa progressão; (b) plasticidade do desenvolvimento psicológico, recusando que mudanças aleatórias, completamente desorganizadas ou totalmente dispersas possam de imediato ser interpretadas como mudanças desenvolvimentais; para serem entendidas e classificadas como desenvolvimentais, tais mudanças devem apresentar um carácter organizado e sistemático num dado momento ou período de tempo.

Ora, é justamente assente nestes princípios que deveremos situar o aparecimento de um vasto e diversificado conjunto de "escolas de desenvolvimento", protagonizadas por autores como Lerner, Baltes, Schaie e outros, todos eles partilhando ideias como a plasticidade da mudança (Lerner, 1984), a multidireccionalidade do desenvolvimento ao longo da vida (Baltes, 1987) e o aumento das diferenças individuais com o avanço da idade (Schaie, 1983). Comum as todas as correntes inspiradas no paradigma contextualista está a convicção de que todas as pessoas, mais novas ou mais velhas, desenvolvem-se, e que os processos e as funções desse desenvolvimento serão tanto melhor compreendidos quanto mais se optar por orientações conceptuais e empíricas baseadas nas relações que se estabelecem entre uma "pessoa em desenvolvimento" e um "contexto em mudança" (Lerner, 1996). O desenvolvimento humano passa a incorporar noções como interacção pessoa-contexto, continuidade, mudança, plasticidade, reportadas sempre a todo o ciclo de vida e não apenas a segmentos dele, sendo estes os princípios básicos que, nas últimas duas décadas, têm estado na origem do aparecimento e da consolidação de uma larga família de teorias e de perspectivas, revelando a existência de uma "adequação activa” do paradigma contextualista ao estudo científico do desenvolvimento (Lerner, 2002, Overton, 2006).

Estamos a referir-nos, nomeadamente, à abordagem ecológica do desenvolvimento humano, ao contextualismo desenvolvimental, à teoria da acção e do controle pessoal sobre o desenvolvimento e à psicologia desenvolvimental do ciclo de vida (Figura 1), modelos que ao longo dos anos têm cruzado e partilhado entre si princípios de natureza conceptual e metodológica, enriquecendo-se mutuamente e oferecendo hoje à ciência desenvolvimental um corpo sólido de conhecimentos cujos principais dados passaremos de seguida em revista, em especial, naquilo que nos possam ajudar a efectuar uma leitura desenvolvimental do processo de envelhecimento. 


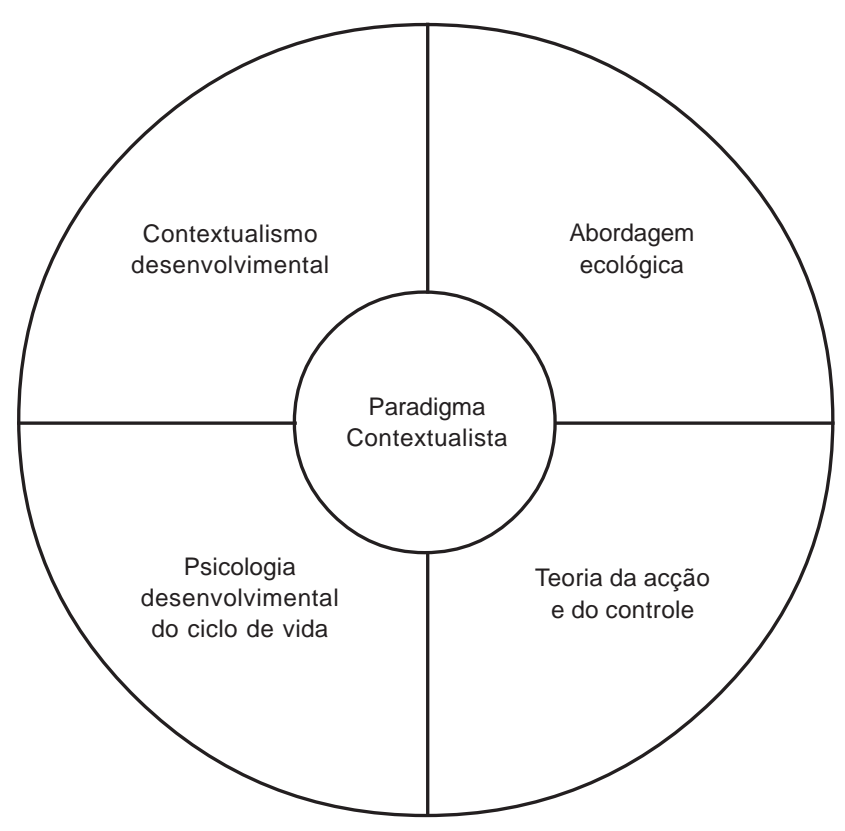

Figura 1. Teorias emergentes do paradigma contextualista.

\section{A Abordagem Ecológica do Desenvolvimento Humano}

Surgida da convicção de que o desenvolvimento e o comportamento humanos só encontram verdadeira significação quando devidamente contextualizados, a abordagem ecológica do desenvolvimento humano apresenta como principal novidade nas suas concepções de indivíduo, de ambiente e, sobretudo, da interacção entre ambos, o reforço da tendência para se olhar simultaneamente no sentido do indivíduo e para além do indivíduo, isto é, para o ambiente ecológico que o rodeia, feito de contextos e de relações.

Assim, numa perspectiva ecológica, o desenvolvimento ocorre na sequência de mudanças duradouras e estáveis na relação entre a pessoa e o seu meio ambiente, sendo caracterizado inicialmente por Bronfenbrenner (1979) com base na aplicação da conhecida fórmula de Kurt Lewin, $B=f$ (P,E), em que o comportamento (B) é uma função das características de cada indivíduo $(\mathrm{P})$ e do seu meio ambiente (E), através de um processo de mútua dependência entre a pessoa e as condições ambientais. Mais tarde, referindo-se à capacidade progressiva do ser humano em descobrir, sustentar e alterar as suas propriedades individuais, Bronfenbrenner alargará esta definição atribuindo à ecologia do desenvolvimento humano a capacidade de nos mostrar como a pessoa se desenvolve ao longo de toda a sua vida, como alcança uma consciência intelectual e emocional e como se torna um protagonista influente no seu meio social, acabando por definir a ecologia do desenvolvimento humano da seguinte forma:

A ecologia do desenvolvimento humano é o estudo científico da acomodação progressiva e mútua, ao longo do ciclo de vida, entre um ser humano activo e em desenvolvimento, e os contextos imediatos e em transformação em que a pessoa vive, sendo este processo afectado pelas relações que se estabelecem entre estes contextos. (Bronfenbrenner, 1989, p. 188).
Em distintos momentos, a visão ecológica do desenvolvimento humano concebe o ambiente ecológico como um conjunto de estruturas repartidas por diferentes níveis que se articulam entre si (Bronfenbrenner, 1979, 1989, 2005). No nível interior, mais elementar, o microsistema é o cenário imediato que contém a pessoa em desenvolvimento, caracterizado por contextos onde os indivíduos podem facilmente envolver-se numa interacção face-a-face (a casa, o grupo de pares, o centro de dia, etc.). O nível seguinte, o mesosistema, conduz já o nosso olhar para lá dos cenários em si mesmos e debruça-se sobre as relações entre os microsistemas, ao passo que o terceiro nível do ambiente ecológico, o exosistema, leva-nos ainda mais longe e levanta a hipótese de o desenvolvimento individual ser afectado por acontecimentos que ocorrem em cenários nos quais a pessoa não está sequer presente. Finalmente, em cada sociedade ou cultura há um modelo de organização social, económica e política - o macrosistema-, a partir do qual faz-se a construção de cada tipo de cenário.

Privilegiando a sistematização do ambiente ecológico no qual o indivíduo se desenvolve, esta postura rompe claramente com uma visão organicista e distancia-se dos modelos estruturais de desenvolvimento, dando ênfase à importância dos factores de socialização e afirmando a plasticidade do desenvolvimento humano. Ao desenvolver-se, a pessoa adquire uma concepção de ambiente ecológico mais alargada e diferenciada, fica mais motivada e preparada para se envolver em actividades que mantêm ou modificam aquele ambiente, e caminha no sentido de alcançar níveis de maior complexidade em forma e em conteúdo (Bronfenbrenner, 1989).

Ao referir-se à sua teoria como "uma concepção desenvolvimental da pessoa em desenvolvimento", Bronfenbrenner sublinha o papel activo dos indivíduos na modelagem das respectivas vidas, o que corresponde a uma visão do desenvolvimento como algo que traduz uma orientação “activa e responsiva” do indivíduo face ao ambiente. Esta orientação vai sofrendo modificações ao longo do ciclo de vida, mas continua a expressar-se em idades mais avançadas de um modo claramente construtivo, o que contraria o que poderíamos aqui designar abreviadamente por uma perspectiva passiva e alienada da velhice:

Em idades mais avançadas, esta tendência [para uma orientação activa e responsiva face ao ambiente ] é expressa através de aspectos como a facilidade para tomar iniciativas sociais; a capacidade para manter relações humanas; a curiosidade; a disposição para manipular, reconstruir e elaborar o ambiente, e de uma concepção do self como um agente activo num mundo que apresenta uma natureza sensível. (Bronfenbrenner, 1989, p. 212).

Utilizando a terminologia seguida pelo próprio Bronfenbrenner, a perspectiva ecológica do desenvolvimento humano afirma-se como um modelo "pós-positivista" de compreensão dos princípios implicados no desenvolvimento psicológico, equiparando a ênfase colocada nas questões biológicas e genéticas ao papel das dimensões históricas e socioculturais implicadas nesse desenvolvimento, sobretudo a partir da adolescência (Bronfenbrenner, Kessel, Kessen 
$\&$ White, 1986). Aqui reside, aliás, o motivo pelo qual, com o avançar da idade, mais importante do que estudar os organismos de per si é proceder ao estudo das "variáveis" com que os indivíduos se confrontam na sua vida, tendo presente que cada ser humano configura um organismo "como um todo, detentor de características genéticas, fisiológicas, emocionais, cognitivas e sociais, que funcionam de modo diferenciado em diferentes cenários e contextos" (Bronfenbrenner, Kessel, Kessen \& White, p. 1219).

Numa visão mais recente, Bronfenbrenner (1999, 2005; Bronfenbrenner \& Morris, 2006) sugere uma nova compreensão do decurso da vida humana segundo uma concepção ecológica de desenvolvimento humano, introduzindo-lhe novos elementos e fazendo emergir uma estrutura mais complexa e mais dinâmica, que recebe a designação de "modelo bioecológico". Para Bronfenbrenner (1999, 2005; Bronfenbrenner \& Morris, 2006), os vectores primordiais que formam o modelo bioecológico incorporam as características do contexto, o factor temporal e a natureza activa dos seres humanos: "dentro dos limites e oportunidades proporcionados pelas condições históricas, culturais, e socioeconómicas em que vivem, os seres humanos influenciam o seu próprio desenvolvimento - para melhor ou para pior - através das suas escolhas e dos seus actos" (Bronfenbrenner, 1999, p. 22). Com efeito, no modelo bioecológico, as características de uma "pessoa em desenvolvimento" num determinado momento da sua história resultam de uma série de efeitos cumulativos/interactivos, pelo que estamos perante um modelo que realça devidamente o carácter activo das pessoas em relação ao seu próprio desenvolvimento, simultaneamente produtos e produtores de desenvolvimento.

\section{O Contextualismo Desenvolvimental}

Para Dixon e Lerner (1992), o contextualismo desenvolvimental explora amplamente as possibilidades de articulação entre distintos princípios paradigmáticos. De facto, um aspecto central desta perspectiva é a convicção de que não existe uma causa única e singular para explicar o desenvolvimento individual, nem o recurso a variáveis internas (biológicas ou psicológicas), interpessoais (relações face-a-face ou em grupos de pares), ou variáveis externas (ambientais ou institucionais), é susceptível, por si só, de explicar as mudanças desenvolvimentais. Para compreender a ocorrência dessas mudanças e o desenvolvimento a elas associado, torna-se imprescindível articular os referidos três níveis de organização e considerar o modo como evolui a relação entre eles: "a estrutura ou padrão de relações entre estes níveis de análise produz o comportamento do indivíduo, e mudanças na forma (configuração) de tais relações produz mudança desenvolvimental” (Dixon \& Lerner, p. 37-38).

Articulando os níveis interno, externo e interpessoal de organização do funcionamento humano, Lerner e BuschRossnagel (1981) apresentaram uma conceptualização de desenvolvimento onde sobressaem as ideias de plasticidade e de natureza interactiva do desenvolvimento humano (indivíduo-cultura), atribuindo aos indivíduos um papel de produtores do seu próprio desenvolvimento. Analisemos com mais detalhe esta noção.
$\mathrm{Na}$ sua obra pioneira, Individuals as producers of their development, Lerner e Busch-Rossnagel (1981) exploram as implicações conceptuais, metodológicas e empíricas da ideia nuclear segundo a qual os indivíduos são produtores do seu desenvolvimento, recorrendo para isso a dois princípios básicos: (a) o da existência de níveis distintos de organização contextual, os quais se encontram em mudança constante, (b) o da integração de cada nível nos restantes. Se o conceito de mudança constante estabelece a inexistência de uniformidade no desenvolvimento e sugere uma multiplicidade de trajectórias desenvolvimentais, o conceito de integração salienta a interligação existente entre todos os níveis de organização, pelo que qualquer mudança deverá ser entendida no quadro de outras mudanças com as quais se possa articular. A esta luz, mesmo a biologia humana é simultaneamente produtora e produto da mudança social e cultural, contrariando a ideia de que será a mudança biológica a dar forma à mudança social (Lerner \& Walls, 1999).

De facto, apesar de defender que o desenvolvimento é geneticamente guiado (Lerner \& Kauffman, 1985), o contextualismo desenvolvimental preconiza que a intervenção nesse desenvolvimento é possível por meio da acção individual, decorrendo daqui uma importante noção no quadro do paradigma contextualista, isto é, a noção de plasticidade: "o ciclo de vida humano é caracterizado pelo potencial para a plasticidade (i.e., mudanças sistemáticas intra-individuais), bem como pelo potencial para a verificação de diferenças interindividuais nessas mudanças" (Lerner \& Walls, 1999, p. 11). Partindo de Brim e Kagan (1980), que haviam já defendido que o decurso do desenvolvimento humano é aberto - "mais aberto do que aquilo que muitos supõem" (p. 1) -, e de Featherman (1983), que destacara a forma como a variabilidade inter-individual se acentua à medida que os anos vão passando - "os adultos não só continuam a desenvolver-se, como tornam-se também menos parecidos uns com os outros à medida que envelhecem" (p. 5) -, o contextualismo desenvolvimental associa a noção de plasticidade às mudanças sistemáticas que ocorrem na estrutura e/ou nas funções individuais, e conceptualiza-a mediante três princípios básicos (Lerner, 1984; Lerner \& Walls, 1999): (a) há múltiplos caminhos possíveis que o desenvolvimento pode percorrer, constituindo esta diversidade a melhor ilustração da existência de um potencial de plasticidade no desenvolvimento humano ao longo da vida, como consequência natural da interacção recíproca entre um indivíduo activo e um mundo em mudança; (b) o interaccionismo dinâmico, presente nas ideias de mudança constante e de integração, acentua a natureza plástica do desenvolvimento psicológico e nega a possibilidade de existência de estádios finais ou uniformes de desenvolvimento; (c) o indivíduo tem um papel activo no seu próprio desenvolvimento, papel esse que deriva do conceito de acção, ou seja, da acção dos indivíduos nos contextos, da acção dos contextos sobre os indivíduos e da acção conjunta indivíduos-contex tos, o quer resulta na consideração de um papel activo da pessoa ao promover mudanças quer no self quer no contex to e torna-a uma produtora do seu desenvolvimento. 
Mas a plasticidade não é total e o próprio Lerner reconhece-o, chamando a atenção para o carácter não equipotencial da plasticidade, ou seja, à medida que o organismo se desenvolve, a extensão de estruturas e funções cujo potencial de plasticidade pode ser aproveitado torna-se cada vez menor (Lerner, 1984). Mais recentemente, Lerner e Walls (1999) falam de uma plasticidade relativa, reafirmando que a plasticidade não é ilimitada mas sempre constrangida, quer devido a causas e acontecimentos passados, quer devido a condições ecológicas e contextuais contemporâneas.

A visão sobre o desenvolvimento humano enunciada originalmente no início dos anos ' 80 por Lerner e BuschRossnagel (1981) acabou por se tornar a origem de numerosos estudos, no sentido de melhor se compreender as bases da relação indivíduo-contexto no quadro de conceitos como plasticidade, mudança e acção (Baltes, 1987; Brandtstadter, 2006; Featherman, 1983; Lerner, 1996; Magnusson, 1996). O próprio Lerner "revisitou" em 1999 o tema da obra publicada em 1981 (Lerner \& Walls, 1999), actualizando-a e concluindo então que, independentemente das contribuições que foram sendo acrescentadas e das revisões que foram sendo feitas, as ideias originalmente enunciadas mantêm-se actuais e ganharam mesmo ao longo dos anos uma importância reforçada, designadamente, (a)o papel que jogam na "produção do desenvolvimento" as múltiplas acções conjuntas verificadas entre indivíduos e contextos, (b) a importância da mudança constante e da integração como dimensões inerentes aos processos de desenvolvimento.

\section{A Teoria da Acção e do Controle Pessoal sobre o Desenvolvimento}

Assumindo uma clara afinidade da sua abordagem teórica com o paradigma contextualista, é em torno de três princípios estruturantes que Brandtstadter (1984) alicerça a teoria da ação e do controle pessoal sobre o desenvolvimento: (a) a plasticidade e a diversidade são atributos do desenvolvimento relacionados com o contexto; é o contex to que favorece o aparecimento de diferenças, quer nos padrões desenvolvimentais, quer nos comportamentos; (b) há limites para a plasticidade, limites para uma concepção voluntariosa do desenvolvimento; se as restrições culturais podem, até certo ponto, ser ultrapassadas, o mesmo já não sucede, por exemplo, com as leis biológicas; (c) é possível compatibilizar a diversidade com a invariância; apesar da dificuldade notória em generalizar os processos e os padrões desenvolvimentais, tal não é razão suficiente para abandonar a ideia de que alguns desses processos e padrões (ligados sobretudo a mecanismos de ordem emocional) possuem uma validade universal.

Para Overton (2006), a teoria da acção em geral e o conceito de controle nela inscrito, representam na perfeição uma abordagem "centrada na pessoa" susceptível de permitir o estudo de processos e operações implicados na atribuição/produção de sentido ao modo como a actividade humana se desenrola, considerando Overton que ao falar-se de acção humana estamos necessariamente a falar também de projectos, intenções, objectivos, motivos, razões, interpretações e por aí adiante, noções às quais a teoria da acção e do controle pessoal recorre frequentemente.

Nesta teoria, o desenvolvimento individual ao longo do ciclo de vida é um processo que se fundamenta e regula através da aç̧ão individual e social. Esta acção é concebida como um construto que é formado (mais do que determinado) através da conjugação de certos atributos, como expectativas, valores e crenças, devendo encarar-se esse desenvolvimento como algo que não pode ser dissociado de uma estrutura mais vasta. Inerente a esta concepção preside, assim, a ideia de que o desenvolvimento humano é também um produto cultural, entendendo-se aqui por cultura todas aquelas condições de vida que são transformadas através de uma aç̧ão intencional, de acordo com as necessidades, exigências e ideais da vida humana e da existência social. Para Brandtstadter (1984), o ambiente cultural funciona como uma "segunda natureza" para o indivíduo, à qual até os processos maturacionais - do desenvolvimento pré-natal ao envelhecimento - estarão submetidos, não podendo serem vistos unicamente como sequências invariantes que seguem as leis da natureza, mas antes serem encarados como processos estrutural e funcionalmente relacionados com uma série de interesses, possibilidades e limitações decorrentes de determinados contextos históricos, sociais e culturais, contextos estes conceptualizados por Brandtstadter como representativos de uma autêntica "ecologia cultural".

Mas em que medida a pessoa regula a sua acção, de forma a atingir o nível de desenvolvimento desejado? E quais serão as limitações esperadas para esse desenvolvimento? A teoria da acção e do controle pessoal sobre o desenvolvimento parte do princípio que cada pessoa se esforça por atingir determinados "fins" ou "objectivos desenvolvimentais", procurando, nessa medida, modelar o seu próprio desenvolvimento através da seleccão e/ou criação de "condições ecológicas artificiais" - por exemplo, um determinado emprego, uma família, um local para viver -, ajustadas quer aos seus interesses, quer às suas capacidades e competências (Brandtstadter, 1990). Esta possibilidade de "construção" ou "produção" do próprio desenvolvimento deve, porém, ser encarada dentro de certos limites. De facto, elementos intencionais e acidentais intervêm sempre na história de vida do indivíduo, sendo julgados pelos indivíduos como circunstâncias que podem ser alteradas, modificadas ou aceites, variando muito de pessoa para pessoa esse julgamento e a acção daí decorrente. Para entender estas diferenças individuais é que Brandtstadter propõe o conceito de controle sobre o desenvolvimento (Brandtstadter, 1984), destacando-se aqui, nomeadamente, o sentido de controle pessoal que se exerce sobre áreas importantes e subjectivas do desenvolvimento.

Este controle, porém, não é total. A pessoa não está só enquanto "produtora" do seu desenvolvimento, havendo diferentes tipos de constrangimentos com que necessita de lidar (leis naturais, restrições éticas e legais, organização dos sistemas sociais, limitações no funcionamento dos orga- 
nismos vivos), esperados e controláveis ou fortuitos e imprevisíveis. Na medida em que o desenvolvimento "implica uma mudança nos padrões transaccionais que relacionam o organismo humano com o seu ambiente físico e social” (Brandtstadter, 1990, p. 160), a regulação desse desenvolvimento e das mudanças que lhe estão associadas ao longo da vida torna-se uma área importantíssima de controle.

Falar-se de controle pessoal sobre o desenvolvimento - que Brandtstadter descreve como "um sentido de controle individual sobre áreas subjectivamente importantes do desenvolvimento pessoal" (Brandtstadter, 1989, p. 96) - implica, justamente, que na base de certas expectativas sociais relativas ao desenvolvimento humano reside a ideia de que cabe ao ser humano controlar activamente o curso da sua vida, esforçando-se por manter um equilíbrio favorável entre ganhos e perdas através de um duplo processo de ajustamento (Brandtstadter, Krampen \& Greve, 1987). Com efeito, se por um lado a pessoa procura ajustar a sua acção individual tendo em vista a concretização de objectivos previamente fixados, por outro lado, perante os insucessos, a pessoa focaliza a atenção na discordância existente entre as suas aspirações e os resultados alcançados, ajustando os objectivos pessoais às suas capacidades e competências. Este duplo processo - ajustamento da acção em função de objectivos pré-determinados e ajustamento de objectivos em função de constrangimentos -, desenrola-se frequentemente de uma forma não consciente e é susceptível de conduzir o indivíduo a estados de perturbação emocional (perda de bem-estar, tristeza ou mesmo depressão), ficando patente a ligação aqui existente entre o controle das crenças e dos objectivos (dimensão cognitiva), o controle da acção (dimensão comportamental) e o controle dos estados emocionais (dimensão afectiva) (Brandtstadter, 1984, 1989).

\section{A Psicologia Desenvolvimental do Ciclo de Vida}

Considerando que o desenvolvimento envolve sempre um processo de mudança e que esta será melhor compreendida se for situada no contex to de acontecimentos antecedentes e subsequentes, Baltes e pesquisadores delimitaram em 1980 a Psicologia Desenvolvimental do ciclo de vida do seguinte modo: "a Psicologia Desenvolvimental do ciclo de vida preocupa-se com a descrição, explicação, e modificação (optimização) dos processos desenvolvimentais no decurso da vida humana, da concepção à morte” (Baltes, Reese \& Lipsitt, 1980, p. 66).

Assim entendido, o desenvolvimento humano será o resultado da interacção entre factores biológicos, históricos e culturais, reflectindo a arquitectura do desenvolvimento individual as relações dinâmicas que entre si estes factores estabelecem, bem como a respectiva evolução ao longo do tempo. Os mesmos autores ressalvam desde logo ser importante não confundir o estudo desenvolvimental relativo ao ciclo de vida com o estudo relativo à idade cronológica, pois tal significaria uma limitação óbvia das possibilidades explicativas deste modelo, tornando-o refém das críticas feitas às teorias de base organicista que fundamentam na idade a explicação para as mudanças desenvolvimentais.
A Psicologia Desenvolvimental do ciclo de vida foi sendo, ao longo dos anos, revista e ampliada pelo próprio Paul Baltes, por colaboradores e por outros autores próximos em termos conceptuais e metodológicos, podendo assinalar-se hoje, como ideias directrizes desta perspectiva, as seguintes proposições (Baltes, 1987, 1993, 1997, 1999, 2005; Baltes \& Baltes, 1990; Baltes, Lindenberger \& Staudinger, 2006; Baltes, Reese \& Lipsitt, 1980; Baltes \& Smith, 2003, 2004; Baltes, Staudinger \& Lindenberger, 1999; Dixon \& Lerner, 1992; Lerner, 2002):

1. O desenvolvimento humano é um processo que se estende ao longo de toda a vida, através da ocorrência de mudanças desenvolvimentais. A Psicologia Desenvolvimental do ciclo de vida preocupa-se com a identificação da forma e do conteúdo das alterações comportamentais que vão ocorrendo durante a vida humana.

2. Tomada como um todo, a noção de desenvolvimento ao longo da vida pode ser apreciada em termos das exigências e das oportunidades com que os indivíduos se defrontam à medida que a vida decorre, não podendo falar-se, por isso, na existência de períodos mais e menos importantes sob o ponto de vista desenvolvimental.

3. Ocorrendo as mudanças em vários níveis de desenvolvimento relacionados entre si, a Psicologia Desenvolvimental do ciclo de vida reconhece no desenvolvimento humano a expressão de princípios ontogénicos e evolutivos; termos como multidireccionalidade e multidimensionalidade (significando, respectivamente, que o desenvolvimento não evolui numa só direcção nem se reduz a uma dimensão apenas), são conceitos frequentes numa abordagem de ciclo de vida e procuram traduzir uma imagem de desenvolvimento que está para além de um simples critério de crescimento em termos de eficácia funcional.

4. A Psicologia Desenvolvimental do ciclo de vida dá ênfase à integração histórica e social da vida dos indivíduos e à influência, no desenvolvimento humano, quer de factores ligados à idade cronológica, quer de outros factores contextuais não ligados à idade (como os acontecimentos de vida, o género, a classe social de pertença ou a etnia).

5. Na base do desenvolvimento encontra-se a plasticidade. Ao longo da sua vida, as pessoas revelam uma grande variabilidade intra-individual e apresentam capacidade (mesmo numa fase avançada da vida) para alterar o curso do seu desenvolvimento, para prevenir a ocorrência de certos comportamentos não desejados, bem como para optimizar os mais interessantes sob o ponto de vista adaptativo. Cada indivíduo possui um dado potencial de plasticidade de desenvolvimento, propriedade observável ao longo de toda a vida mas que diminui à medida que os recursos, nomeadamente de ordem biológica, vão também diminuindo.

6. Dado existir sempre um certo potencial de plasticidade, existe igualmente um potencial de intervenção no 
desenvolvimento psicológico de cada indivíduo ao longo da sua vida. Todavia, à medida que o organismo se desenvolve, a extensão de estruturas e funções cujo potencial de plasticidade pode ser aproveitado torna-se cada vez menor, devido a constrangimentos de ordem biológica e sociocultural; este carácter não equipotencial da plasticidade implica, pois, que haja períodos da vida humana que se mostrem mais favoráveis à intervenção no desenvolvimento do que outros.

7. A Psicologia Desenvolvimental do ciclo de vida dá relevo a um desenvolvimento por oscilações, através de uma alternância permanente e dinâmica entre crescimento (revelador de ganhos desenvolvimentais) e declínio (revelador de perdas). Esta alternância entre ganhos e perdas sugere que o desenvolvimento deva ser definido como qualquer mudança na capacidade adaptativa do organismo, seja ela positiva ou negativa.

8. Qualquer progressão desenvolvimental exibe simultaneamente a emergência de novas capacidades adaptativas e a perda de capacidades previamente existentes, não existindo mudanças desenvolvimentais durante o decurso da vida que traduzam unicamente ganhos. O processo adaptativo obedece a um modelo composto por três mecanismos interactivos - "selecção, optimização e compensação”- que, tomados em conjunto, permitem compreender como os seres humanos se adaptam às circunstâncias internas e externas que atravessam ao longo do ciclo de vida.

9. Através da integração de vários níveis desenvolvimentais e da interacção dinâmica organismo-ambiente, os indivíduos participam activamente na modelação do seu próprio ambiente, o qual, por seu lado, também modela o desenvolvimento individual; dito de outro modo, os indivíduos são produtores e produtos do seu próprio desenvolvimento. Nesta medida, é possível conceber que, em larga medida, as pessoas escolhem (ou criam) o contex to em que desejam viver e desenvolver-se, um contex to que lhes permita optimizar a direcção do seu desenvolvimento.

10. Finalmente, para ser profícuo, o estudo do desenvolvimento humano deve ser realizado numa perspectiva multidisciplinar. Aliás, a própria Psicologia Desenvolvimental do ciclo de vida inspirou-se noutras fontes para delimitar os seus princípios básicos: (a) o trabalho dos biólogos relativo à epigénese probabilística forneceu as bases para se estabelecer o carácter descontínuo do desenvolvimento, (b) a explicação das mudanças desenvolvimentais associadas aos factores socio-históricos resulta de uma interpretação histórica da realidade, (c) o contributo dos sociólogos é fundamental para se compreender o modo como o curso da vida está estruturado, quer pela tomada de papéis sociais diferenciados consoante a idade, quer pela forma como os indivíduos vão correspondendo às expectativas que sobre eles recaem em diferentes momentos da sua existência.

\section{As Limitações do Contextualismo}

Uma visão de conjunto das perspectivas que acabámos de analisar (Tabela 1 na próxima página) permite-nos constatar como, no quadro de um paradigma contextualista, questões importantes relativas quer ao processo, quer ao próprio significado do desenvolvimento humano, tiveram oportunidade de emergir e de fazer da ciência desenvolvimental uma área de estudo e de pesquisa que aproxima diferentes correntes de pensamento, da Biologia à Psicologia e desta à Antropologia e à Sociologia.

Esta aproximação tem-se revelado extremamente útil na procura de respostas para alguns temas relevantes no estudo do desenvolvimento humano. Ao encarar o desenvolvimento como um fenómeno biopsicossocial, que envolve e incorpora níveis de organização muito diversos entre si, da genética molecular às dinâmicas histórica e sociocultural, o paradigma contextualista assume-se como uma importante base teórica e metodológica para a descrição e, sobretudo, para a explicação da variabilidade inter-individual e da plasticidade intra-individual ao longo da vida humana.

Não significa isto, obviamente, que as perspectivas que têm derivado do paradigma contextualista respondam a todas as questões relativas ao desenvolvimento humano, ou estejam isentas de críticas. Aliás, se por um lado a aproximação de distintas correntes de pensamento pode proporcionar uma visão mais ampla e compreensiva do comportamento e do desenvolvimento humanos, há igualmente quem, por outro lado, alimente desconfianças relativamente à possibilidade de o contextualismo, devido ao seu carácter disperso, poder gerar teorias do desenvolvimento humano consistentes.

Um dos aspectos que mais frequentemente tem sido apontado como um "problema por resolver" das perspectivas inspiradas pelo contextualismo prende-se com o tratamento dado por este paradigma à relação entre o organismo e o ambiente, chegando mesmo Dowd (1990) a afirmar que essa relação "é muito primitiva” (p. 139). No essencial, estas posições críticas destacam o facto de o contextualismo, por enfatizar amplamente a importância do "contexto", perder de vista a capacidade criadora e transformadora intrínseca ao ser humano, minimizando o respectivo papel no acto de se desenvolver e de, ao fazê-lo, modificar positivamente o que o rodeia (Dowd, 1990).

\section{O Estudo do Envelhecimento numa Perspectiva Desenvolvimental}

Uma visão de ciclo de vida do desenvolvimento humano implica a consideração de outros factores para além da idade, nomeadamente, factores evolutivos ligados à história e a acontecimentos não-normativos. A relação dialéctica, necessária e desejável, entre quadros teóricos e metodologias de investigação, conduz-nos ao reconhecimento do papel que a psicologia do ciclo de vida tem desempenhado no avanço da metodologia de investigação do desenvolvimento humano em geral, e no estudo do envelhecimento em particular, chamando a atenção, nomeadamente, para a intervenção de outros factores no desenvolvimento para além 
Tabela 1.

Visão de conjunto das perspectivas inspiradas no paradigma contextualista

\begin{tabular}{|c|c|c|c|}
\hline Abordagem ecológica & $\begin{array}{c}\text { Contextualismo } \\
\text { desenvolvimental }\end{array}$ & $\begin{array}{c}\text { Teoria da acção } \\
\text { e do controle pessoal }\end{array}$ & $\begin{array}{c}\text { Psicologia Desenvolvimental } \\
\text { do ciclo de vida }\end{array}$ \\
\hline $\begin{array}{l}\text { Desenvolvimento ocorre na } \\
\text { sequência de mudanças } \\
\text { duradouras e estáveis na } \\
\text { relação entre a pessoa e o seu } \\
\text { meio ambiente. } \\
\text { A visão ecológica do } \\
\text { desenvolvimento humano } \\
\text { concebe o ambiente ecológico } \\
\text { como um conjunto de } \\
\text { estruturas repartidas por } \\
\text { difer en tes nív eis que } \\
\text { s e articulam entre si: } \\
\text { microsistema mesosistema, } \\
\text { exosistema macrosistema. } \\
\text { Esta abordagem sublinha o } \\
\text { papel activo dos indivíduos } \\
\text { na modelagem das } \\
\text { respectivas vidas, o que } \\
\text { corresponde a uma visão do } \\
\text { desenvolvimento como algo } \\
\text { que traduz uma orientação } \\
\text { “activa e responsiva” do } \\
\text { indivíduo face ao ambiente. } \\
\text { Mais recentementeéproposta } \\
\text { uma estrutura mais complexa } \\
\text { e mais dinâmica, que recebe } \\
\text { a designação de “modelo } \\
\text { bioecológico”, cujos vectores } \\
\text { primordiais incorporam as } \\
\text { características do contexto, o } \\
\text { desenvolvimento, do qual são } \\
\text { simultaneamente produtos e } \\
\text { produtores. } \\
\text { activa dos seres humanos. Á luz } \\
\text { do modelo bioecológico, as } \\
\text { características de uma } \\
\text { “pessoa em desenvolvimento” } \\
\text { num determinado momento } \\
\text { uma sua história resultam de } \\
\text { interactivos, pelo que estamos }\end{array}$ & $\begin{array}{l}\text { Conceptualização de desen- } \\
\text { volvimento onde sobressaem } \\
\text { as ideias de plasticidade e de } \\
\text { natureza interactiva do } \\
\text { d e s e n v o l v i m e n t o } \\
\text { (in divíd u o - c u l u r a), } \\
\text { atribuindo aos indivíduos } \\
\text { um papel de produtores do } \\
\text { seu próprio desenvol- } \\
\text { vimento. } \\
\text { Defendendo que o desenvol- } \\
\text { vimento é geneticamente } \\
\text { guiado, a intervenção nesse } \\
\text { desenvolvimento é possível } \\
\text { por meio da acção individual, } \\
\text { decorrendo daqui a noção de } \\
\text { plasticidade. Todavia, à } \\
\text { medida que o organismo se } \\
\text { desenvolve, a extensão de } \\
\text { estruturas e funções cujo } \\
\text { potencial de plasticidade } \\
\text { pode ser aproveitado torna- } \\
\text { se cada vez menor - } \\
\text { plasticidade relativa (quer } \\
\text { devido a causas e aconteci- } \\
\text { mentos passados, quer } \\
\text { devido a condições ecoló- } \\
\text { gicas e contextuais contem- } \\
\text { porâneas). Há múltiplos } \\
\text { caminhos possíveis que o } \\
\text { desenvolvimento pode per- } \\
\text { correr, constituindo esta } \\
\text { diversidade a melhor ilustra- } \\
\text { ção da existência de um } \\
\text { potencial de plasticidade no } \\
\text { desenvolvimento humano ao } \\
\text { longo da vida, como conse- } \\
\text { muência natural da interação } \\
\text { rectivo e um mundo em }\end{array}$ & $\begin{array}{l}\text { O desenvolvimento indivi- } \\
\text { dual ao longo do ciclo de vida } \\
\text { é um processo que se } \\
\text { fundamenta e regula através } \\
\text { da acção individual e social. } \\
\text { Esta acção é concebida como } \\
\text { um construto que é formado } \\
\text { (mais do que determinado) } \\
\text { através da conjugação de } \\
\text { certos atributos, como } \\
\text { expectativas, valores e } \\
\text { crenças. } \\
\text { O ambiente cultural funcio- } \\
\text { na como uma “segunda } \\
\text { natureza” para o indivíduo, } \\
\text { à qual até os processos } \\
\text { maturacionais - do desen- } \\
\text { volvimento pré-natal ao } \\
\text { envelhecimento - estarão } \\
\text { submetidos, tendo em conta } \\
\text { uma série de interesses, } \\
\text { possibilidades e limitações } \\
\text { decorrentes de determina- } \\
\text { dos contextos históricos, } \\
\text { volvimento. } \\
\text { sociais e culturais. } \\
\text { Cada pessoa esforça-se por } \\
\text { atingir determinados "fins” } \\
\text { ou "objectivos desenvolvi- } \\
\text { mentais”, procurando mode- } \\
\text { lar o seu próprio desen- } \\
\text { volvimenteresses, quer às suas } \\
\text { seleccão e/ou criação de } \\
\text { “condições ecológicas } \\
\text { artificiais” - por exemplo, } \\
\text { um determinado emprego, } \\
\text { uma família, um local para } \\
\text { viver }\end{array}$ & $\begin{array}{l}\text { O desenvolvimento humano } \\
\text { será o resultado da interacção } \\
\text { entre factores biológicos, } \\
\text { históricos e culturais, } \\
\text { reflectindo a arquitectura do } \\
\text { desenvolvimento individual } \\
\text { as relações dinâmicas que } \\
\text { entre si estes factores } \\
\text { estabelecem, bem como a } \\
\text { respectiva evolução ao longo } \\
\text { do tempo. } \\
\text { O desenvolvimento humano } \\
\text { é umprocesso que se estende ao } \\
\text { longo de toda a vida, através } \\
\text { da ocorrência de mudanças } \\
\text { desenvolvimentais, não } \\
\text { podendo falar-se, por isso, na } \\
\text { existência de períodos mais } \\
\text { e menos importantes sob o } \\
\text { ponto de vista desenvol- } \\
\text { vimental. } \\
\text { A Psicologia Desenvol- } \\
\text { vimental do ciclo de vida dá } \\
\text { ênfase à integração histórica } \\
\text { e social da vida dos indi- } \\
\text { víduos e à influência, no } \\
\text { desenvolvimento humano, } \\
\text { quer de factores ligados àidade } \\
\text { cronológica, quer de outros } \\
\text { factores contextuaisnão ligados } \\
\text { à idade. } \\
\text { A Papsicologia Desenvol- } \\
\text { organismo. } \\
\text { vimental do ciclo de vida dá } \\
\text { relevo a um desenvol- } \\
\text { vimento por oscilações, } \\
\text { através de uma alternância } \\
\text { permanente e dinâmica entre }\end{array}$ \\
\hline
\end{tabular}

da idade. Para Vandenplas-Holper (1998), este contributo tanto se tem dado ao nível de investigações de grande envergadura, que procuram "estudar longitudinalmente as mudanças intra-individuais ligadas à idade e os efeitos ligados às alterações socio-históricas que caracterizam as diferentes coortes", como ao nível de investigações mais mo- destas, “[que] acompanham, no curto prazo, pessoas confrontadas com acontecimentos de vida marcantes para as suas vidas" (p. 248). Num e noutro caso, conclui a autora, o estudo da estabilidade e da mudança na conduta humana e ao nível das diferenças inter-individuais constituem duas preocupações sempre presentes na forma como a psicologia 
do ciclo de vida encara o contributo da investigação para o avanço da ciência desenvolvimental.

Quanto às diferenças inter-individuais, importa aqui registar as conclusões a que Schaie (1996) chegou acerca do desenvolvimento das capacidades cognitivas, ao destacar o importante papel desempenhado por aquilo que o autor designa por antecedentes das diferenças inter-individuais. Para Schaie (1996), a consideração de tais antecedentes revelase de enorme importância não só para a análise das diferenças entre os indivíduos quanto à sua performance cognitiva, mas igualmente no que respeita a outros aspectos do seu funcionamento durante a idade adulta e a velhice. Através de uma análise efectuada a um vasto conjunto de estudos inspirados no quadro da psicologia do ciclo de vida, Vandenplas-Holper (1998) sublinha que o grau de escolarização é, de entre os antecedentes das diferenças individuais, uma das variáveis preditivas de envelhecimento bem sucedido mais importantes:

Um certo número de estudos evidencia relações bastante fortes entre o nível de escolarização e diferentes aspectos do desenvolvimento na idade adulta e durante a velhice; . . . as pessoas cujo nível de escolarização é elevado obtêm resultados superiores àquelas cujo nível de escolarização é fraco. (p. 252).

Às duas preocupações atrás assinaladas, Baltes (1987) acrescenta uma terceira, que consiste no estudo das mudanças intra-individuais - as quais devem ser interpretadas à luz das teorias do desenvolvimento psicológico -, e ainda uma quarta preocupação, o estudo dos efeitos ligados à coorte - devendo tal estudo ser feito a partir de uma abordagem interdisciplinar. Segundo Baltes, uma abordagem de natureza interdisciplinar constitui, aliás, uma modalidade privilegiada de investigação para a Psicologia Desenvolvimental do ciclo de vida, considerando mesmo que o estudo da forma como as mudanças socio-históricas afectam o desenvolvimento humano das diferentes coortes, funciona como um contexto privilegiado de colaboração entre psicólogos, sociólogos e historiadores. Também Lehr (1999) enuncia as vantagens da abordagem interdisciplinar nos estudos sobre o envelhecimento, defendendo que o recurso a uma equipa de investigadores procedentes de vários campos disciplinares pode contribuir significativamente para reduzir os problemas técnicos e metodológicos que normalmente andam associados à pesquisa neste domínio.

Para além dos efeitos ligados à idade e à coorte, Baltes (1987) destaca a importância que os acontecimentos de vida e as transições daí decorrentes adquirem para a compreensão dos factores envolvidos no desenvolvimento psicológico. A este respeito, os trabalhos de natureza correlacional (sobretudo) que a Psicologia Desenvolvimental do ciclo de vida tem produzido ao longo dos anos ajudaram a colocar em evidência as relações que se manifestam entre as reacções face aos acontecimentos de vida marcantes e a saúde física ou bem-estar psicológico daí decorrentes (Vandenplas-Holper, 1998). Muitos destes trabalhos, levados a cabo usando estratégias quer transversais quer longitudinais, contribuíram para demonstrar que as situações de transição (vividas com maior ou menor stresse) podem revelar-se uma oportunidade para o desenvolvimento pessoal, variando a sua repercussão sobre o bem-estar psicológico e a saúde dos indivíduos de acordo com a interferência de outras variáveis.

Em suma, o estudo do envelhecimento considerado na óptica da psicologia do ciclo de vida, enuncia basicamente as seguintes três variáveis explicativas da mudança desenvolvimental: idade, coorte, acontecimentos de vida. Tendo em conta, como escrevemos atrás, que a psicologia do desenvolvimento humano ao longo do ciclo de vida não dispõe até ao momento de uma teoria unificadora, é natural que as perspectivas teóricas que se inscrevem neste grande quadro de referência tenham desenvolvido múltiplas abordagens metodológicas, mais ou menos específicas, consoante a natureza das problemáticas em estudo. Do conjunto de temas mais frequentemente evidenciados pelos autores e pelos modelos teóricos globalmente alinhados numa visão desenvolvimental de ciclo de vida, poderíamos sinalizar dois tópicos que têm adquirido uma expressão mais visível entre os investigadores conotados com a Psicologia Desenvolvimental do ciclo de vida: (a) continuidade/ descontinuidade, (b) multilinearidade/ multidimensionalidade.

A problemática da continuidade versus descontinuidade do desenvolvimento constituiu, desde o início, uma noção chave no quadro da concepção de desenvolvimento psicológico preconizada por Baltes e pesquisadores (Baltes, 1987, 1993; Baltes, Reese \& Lipsitt, 1980). Para eles, o desenvolvimento é essencialmente de cariz descontínuo, muito embora Vandenplas-Holper (1998) recuse esta generalização, afirmando "que nenhum facto empírico pareça sustentar uma tal afirmação” (p. 255). Tal não será, porém, completamente verdade, se pensarmos nos dados a que chegaram dois estudos longitudinais realizados em épocas distintas junto de populações idosas: (a) no Estudo Longitudinal de Bona sobre o envelhecimento (Rudinger \& Thomae, 1990), os autores tiveram oportunidade de constatar que, ao longo da velhice, as pessoas ajustam as suas representações cognitivas da realidade ou modificam o seu comportamento social, no que poderá ser entendido como uma verdadeira alteração de estratégia adaptativa; (b) bem mais recentemente, o Estudo BASE (Baltes \& Mayer, 1999) permitiu comprovar que a " $4{ }^{\mathrm{a}}$ idade" não é uma simples continuação da " $3^{\mathrm{a}}$ idade", sucedendo uma efectiva descontinuidade em termos da capacidade adaptativa individual da $3^{\mathrm{a}}$ para a $4^{\mathrm{a}}$ idade, no sentido de um progressivo declínio de funções.

O que é verdade é que, ao mesmo tempo que Baltes e pesquisadores acentuam a vertente da descontinuidade, Brandtstadter e seus pares socorrem-se de uma série de estudos realizados à luz da teoria da acção e do controle pessoal para defender um ponto de vista em que o selfé encarado como um sistema dinâmico que, de uma forma activa, defende-se da descontinuidade e da desestabilização, procurando prevenir ou reduzir as discrepâncias que possam verificar-se entre o self actual e o self ideal (Brandtstadter \& Greve, 1994; Brandtstadter, Rothermund \& Schmitz, 1997). $\mathrm{O}$ facto de abordagens próximas entre si quanto à raiz de 
inspiração paradigmática chegarem a conclusões distintas não significa, contudo, que elas sejam contraditórias, sendo preferível admitir, como o faz Vandenplas-Holper (1998), que “as noções de 'continuidade' e de 'descontinuidade' aparecem assim como multiformes; os diferentes autores dãolhes significados muito diferentes" (p. 256).

A convicção de Baltes segundo a qual o desenvolvimento psicológico ocorre de uma forma simultaneamente multilinear e multidimensional tem encontrado um eco especial, sob o ponto de vista empírico, em investigações que se debruçam sobre dimensões específicas do funcionamento psicológico, como é o caso do funcionamento cognitivo. Assim, quer o Estudo Longitudinal de Seattle (Schaie, 1996), quer o Estudo BASE (Baltes \& Mayer, 1999), insistem na existência de reservas cognitivas em pessoas de idade avançada, possibilitando aos adultos e idosos continuarem a desenvolverem as suas capacidades cognitivas enquanto o estado físico e a saúde o permitirem.

Os dados assim obtidos têm acabado igualmente por reforçar um dos alicerces em que assenta a Psicologia Desenvolvimental do ciclo de vida, ou seja, a viabilidade da optimização do desenvolvimento psicológico, quer mediante a implementação de intervenções intencionais e deliberadas nesse sentido, quer mediante a criação de contextos de vida estimulantes. De facto, a partir do momento em que investigações como as atrás referidas comprovaram que as pessoas adultas e idosas evidenciam uma enorme plasticidade, é possível então conceber programas de estimulação (cognitiva, social, etc.) que retardem ou invertam mesmo o declínio das respectivas capacidades, como é o caso do programa Viver com Vitalidade (FernándezBallesteros, 2002).

Trata-se, no fundo, de uma demonstração absoluta da "utilidade prática” da investigação psicológica na área do envelhecimento, tornando visível a convicção da utilidade não apenas estritamente científica mas igualmente sociopolítica da pesquisa neste domínio, sublinhada tanto por Schroots e Birren (1993) a propósito da investigação de tipo longitudinal, como por Schaie e Hofer (2001) a propósito da investigação de tipo transversal. Do que não restam dúvidas, aliás, é que a pesquisa desenvolvimental no domínio do envelhecimento encontra-se em enorme expansão, quer em termos de áreas de investigação, quer em termos de abordagens metodológicas (Rudinger \& Rietz, 2001).

Apesar de a diversidade de tópicos de pesquisa continuar ainda muito assente em "orientações clássicas” (qualidade de vida, personalidade, saúde e bem-estar psicológico, dimensões de funcionamento psicológico, relações sociais e familiares, adaptação a acontecimentos de vida, etc.), o que surge agora em nossa opinião com bastante impacto é a adopção de metodologias de investigação muito diversas entre si e apresentando mesmo um carácter francamente inovador, procurando resistir ao "estudo laboratorial" das variáveis implicadas no processo de envelhecimento e insistindo na criação de uma "nova agenda" de investigação psicológica neste domínio, concedendo uma maior atenção às histórias de vida e aos percursos individuais de envelhe- cimento: "Esta perspectiva pode ajudar-nos a ir mais além do estudo habitualmente trivial e técnico em torno de variáveis, olhando para as alegrias e tragédias das vidas reais" (Daatland, 2003, p. 200).

Noutro plano e tendo presente uma aproximação holística ao desenvolvimento individual, Bergman (2004) alerta para as limitações dos métodos estandardizados orientados para o estudo de variáveis pré-definidas, os quais fornecem uma informação limitada acerca da dinâmica pessoal do desenvolvimento: "ao nível individual, o que se esconde por detrás de um coeficiente de correlação?”. Este autor propõe, em alternativa, o recurso a métodos de natureza exploratória e a métodos baseados em modelos, por meio dos quais seja possível proceder, por exemplo, à classificação de trajectórias desenvolvimentais dinâmicas e não-lineares, estudando "histórias de vida individuais" e fazendo uso de metodologias intensivas no estudo do envelhecimento como uma ferramenta da maior "utilidade e sentido prático" em tal domínio.

\section{Algumas Ideias Conclusivas}

Em primeiro lugar, a visão geral de que os indivíduos são produtos e produtores do seu próprio desenvolvimento ajudanos definitivamente a conceber a mudança ontogenética não apenas como um resultado mas também como um alvo intencional de acção humana, valorizando uma dimensão básica do desenvolvimento humano, ou seja, o facto de que o indivíduo desempenha um papel activo na construção do seu próprio desenvolvimento. A possibilidade de os indivíduos poderem seleccionar ou criar contextos com os quais possam "casar" os seus interesses e os seus potenciais de desenvolvimento caminha a par com uma atitude positiva e confiante face à vida e ao futuro, e toma a intencionalidade como uma dimensão indispensável para explicar o desenvolvimento psicológico e compreender o modo como as pessoas constroem as diversas fases do seu desenvolvimento pessoal ao longo do ciclo de vida.

Em segundo lugar, as noções aqui defendidas obrigamnos a defender a existência de um desenvolvimento intencional - ideia central em todas as perspectivas teóricas que aqui analisámos - que assume uma preponderância especial durante períodos de transição (da adolescência para a vida adulta, desta para a velhice...), quando as tarefas desenvolvimentais relativas à (re)definição de um "eu” tornam-se preocupações centrais e mobilizam os recursos individuais de adaptação. Retomando a introdução deste texto, esta concepção apresenta, entre outras, a vantagem de permitir ultrapassar a antiga dicotomia "nature vs. nurture" relativa às causas do desenvolvimento humano, particularmente em termos do estabelecimento de uma prioridade causal entre as duas categorias quanto à maior ou menor importância de cada uma delas sobre o desenvolvimento. Com efeito, a consideração simultânea da possibilidade de se exercer controlo intencional sobre o desenvolvimento e da importância primordial da plasticidade humana na forma como essa intencionalidade age, reflecte bem a integração de dados provenientes da biologia e da cultura; 
se é verdade que a biologia estabelece normas que limitam os resultados desenvolvimentais possíveis, também é verdade que a cultura - quer a colocada à disposição do indivíduo, quer a criada por ele - pode compensar, em larga medida, lacunas em termos de especialização adaptativa.

Em terceiro lugar, é baseada nesta ligação entre aç̧ão pessoal e desenvolvimento humano que a consideração de processos de desenvolvimento intencional (materializados através de crenças, valores, objectivos, acções...), sujeitos a mudanças ao longo do ciclo de vida, deve levar-nos a analisar constantemente constructos diversos, como "tarefas de desenvolvimento", "objectivos desenvolvimentais" e outros. Assim, por exemplo, o desenvolvimento psicológico reveste-se de novos significados em resposta às tarefas de desenvolvimento com que os indivíduos se confrontam e aos papéis sociais que desempenham à medida que se movem na vida, sofrendo as ambições pessoais ajustamentos constantes face às alterações que ocorrem nos recursos disponíveis. A transição da idade adulta para a velhice constitui, de um ponto de vista desenvolvimental, um caso paradigmático da necessidade de serem efectuados ajustamentos desta natureza. $\mathrm{O}$ fenómeno de encurtamento de recursos (biológicos, materiais, sociais) que, tipicamente, acompanha o envelhecimento, pressiona o indivíduo a seleccionar objectivos e a rentabilizar os recursos funcionais ainda disponíveis no sentido da escolha e da criação de ambientes onde as suas capacidades e competências individuais possam ser utilizadas e expressas nos níveis mais elevados e diferenciados que for possível.

Finalmente, a análise conjunta das perspectivas que acabámos de analisar permite-nos constatar como, sob um ponto de vista desenvolvimental, questões importantes relativas quer ao processo, quer ao próprio significado do desenvolvimento psicológico, tiveram oportunidade de emergir e de fazer da ciência desenvolvimental (Bornstein \& Lamb, 2005; Lerner, 2006) uma área de estudo e de pesquisa que aproxima diferentes correntes de pensamento, da biologia à psicologia e desta à antropologia e à sociologia. Esta aproximação tem-se revelado extremamente útil na procura de respostas para alguns temas relevantes no estudo do desenvolvimento humano. Ao encarar o desenvolvimento como um fenómeno biopsicossocial, que envolve e incorpora níveis de organização muito diversos entre si, da biologia (Gottlieb, Wahlsten \& Lickliter, 2006) e genética (Overton, 2003) às dinâmicas histórica e sociocultural (Elder \& Shanahan, 2006), o paradigma contextualista assume-se como uma importante base teórica e metodológica para a descrição e, sobretudo, para a explicação da variabilidade inter-individual e da plasticidade intra-individual ao longo da vida humana.

Como o próprio Baltes afirma (Baltes, Staudinger \& Lindenberger, 1999), o futuro da Psicologia Desenvolvimental dependerá, em larga medida, do modo como as ideias teóricas e empíricas que a visão desenvolvimental do ser humano encerra se revelarem úteis não só para o campo da psicologia do desenvolvimento, mas também para outras especialidades da ciência psicológica, como a Psicologia Clínica, a Psicologia Social, a Psicologia da Saúde e a Psicologia da Personalidade.

\section{Referências}

Baltes, P. (1987). Theoretical propositions of life-span developmental psychology: On the dynamics between growth and decline. Developmental Psychology, 23(5), 611-626.

Baltes, P. (1993). The aging mind: potential and limits. The Gerontologist, 33, 580-594.

Baltes, P. (1997). On the incomplete architecture of human ontogeny: Selection, optimization, and compensation as foundation of developmental theory. American Psychologist, 52, 366-380.

Baltes, P. (1999, August). How we master life: The orchestration of selection, optimization and compensation. Trabalho apresentado na 5th European Conference on Psychological Assessment, Patras, Greece.

Baltes, P. (2005, June). Psychological model of successful aging. Trabalho apresentado no 18 th World Congress of Gerontology, Rio de Janeiro, RJ.

Baltes, P., \& Baltes, M. (1990). Psychological perspectives on successful aging: The model of selective optimization with compensation. In P. Baltes \& M. Baltes (Eds.), Successful Aging: Perspectives from the Behavioral Sciences (pp. 1-34). Cambridge, UK: Cambridge University Press.

Baltes, P., Lindenberger, U., \& Staudinger, U. (2006). Life-span theory in developmental psychology. In R. Lerner (Ed.), Handbook of Child Psychology. Vol.1: Theoretical Models of Human Development ( ${ }^{\text {th }}$ ed., pp. 569-664). Hoboken, NJ: Wiley.

Baltes, P., \& Mayer, K. (Eds.). (1999). The Berlin Aging Study: Aging. from 70 to 100. Cambridge, UK: Cambridge University Press.

Baltes, P., Reese, H., \& Lipsitt, L. (1980). Life-span developmental psychology. Annual Review of Psychology, 31, 65-110.

Baltes, P., Staudinger, U., \& Lindenberger, U. (1999). Lifespan psychology: Theory and application to intellectual functioning. Annual Review of Psychology, 50, 471-507.

Baltes, P., \& Smith, J. (2003). New frontiers in the future of aging: From successful aging of the young old to the dilemmas of the fourth age. Gerontology, 49, 123-135.

Baltes, P., \& Smith, J. (2004). Lifespan psychology: From developmental contextualism to developmental biocultural coconstructivism. Research in Human Development, 1(3), 123-144.

Bergman, L. (2004, July). A holistic approach to individual development: Some methodological considerations. Trabalho apresentado no $18^{\text {th }}$ Biennial Meeting of the International Society for the Study of Behavioral Development, Ghent, Belgium.

Bornstein, M., \& Lamb, M. (Eds.). (2005). Developmental science: An advanced textbook ( $5^{\text {th }}$ ed.). Mahwah, NJ: Erlbaum.

Brandtstadter, J. (1984). Personal and social control over development: Some implications of an action perspective in life-span developmental psychology. In P. Baltes \& O. Brim (Eds.), Lifespan development and behaviour: Vol. 6. New York: Academic Press.

Brandtstadter, J. (1989). Personal self-regulation of development: Cross-sequential analyses of development-related control beliefs and emotions. Developmental Psychology, 25, 96-108.

Brandtstadter, J. (1990). Commentary. Human Development, 33, 160-164. Brandtstadter, J. (2006). Action perspectives on human development. In R. Lerner (Ed.), Handbook of Child Psychology. Vol.1: Theoretical Models of Human Development ( $6^{\text {th }}$ ed., pp. 516-568). Hoboken, NJ: Wiley. 
Brandtstadter, J., \& Greve, W. (1994). The aging self: Stabilizing and protective processes. Developmental Review, 14, 52-80.

Brandtstadter, J., Krampen, G., \& Greve, W. (1987). Personal control over development: Effects on the perception and emotional evaluation of personal development in adulthood. International Journal of Behavioral Development, 10, 1, 99-120.

Brandtstadter, J., Rothermund, K., \& Schmitz, U. (1997). Coping resources in later life. European Journal of Applied Psychology, 47, 107-114.

Brim, O., \& Kagan, J. (1980). Constancy and change in human development. Cambridge, MA: Harvard University Press.

Bronfenbrenner, U. (1979). The ecology of human development. Cambridge, MA: Harvard University Press.

Bronfenbrenner, U. (1989). Ecological systems theory. In R. Vasta (Ed.), Annals of Child Development: Vol. 6 (pp. 187-249). London: JAI Press.

Bronfenbrenner, U. (1999). Environments in developmental perspective: Theoretical and operational models. In S. Friedman \& T. Wachs (Eds.), Measuring environment across the life span. Emerging methods and concepts (pp. 3-28). Washington, DC: American Psychological Association.

Bronfenbrenner, U. (2005). Making humans beings human: Bioecological perspectives on human development. Thousand Oaks, CA: Sage.

Bronfenbrenner, U., \& Morris, P. (2006). The bioecological model of human development. In R. Lerner (Ed.), Handbook of Child Psychology: Vol. 1. Theoretical models of human development $\left(6^{\text {th }}\right.$ ed.). Hoboken, NJ: Wiley.

Bronfenbrenner, U., Kessel, F., Kessen, W., \& White, S. (1986). Toward a critical social history of developmental psychology. American Psychologist, 41(11), 1218-1230.

Clarke-Stewart, A., Perlmutter, M., \& Friedman, S. (1988). Lifelong human development. New York: John Wiley \& Sons.

Daatland, S. (2003). From variables to lives: Inputs to a fresh agenda for psychological aging research in Norway. European Psychologist, 8(3), 200-207.

Dixon, R., \& Lerner, R. (1992). A history of systems in developmental psychology. In M. Bornstein \& M. Lamb (Eds.), Developmental Psychology: An advanced textbook ( $3^{\text {rd }}$ ed., pp. 135). Hillsdale, NJ: Lawrence Erlbaum.

Dowd, J. (1990). Ever since Durkheim: The socialization of human development. Human Development, 33, 138-159.

Elder, G., \& Shanahan, M. (2006). The life course and human development. In R. Lerner (Ed.), Handbook of Child Psychology. Vol.1: Theoretical Models of Human Development ( $6^{\text {th }}$ ed.). Hoboken, NJ: Wiley.

Featherman, D. (1983). Life-span perspectives in social science research. In P. Baltes \& O. Brim, Jr. (Eds.), Life-Span Development and Behavior: Vol. 5 (pp. 1-57). New York: Academic Press.

Fernández-Ballesteros, R. (Ed.). (2002). Vivir con vitalidad. Madrid, España: Pirámide.

Fonseca, A. M. (2005). Desenvolvimento humano e envelhecimento. Lisboa, Portugal: Climepsi.

Gottlieb, G., Wahlsten, D., \& Lickliter, R. (2006). The significance of biology for human development: A developmental psychobiological systems view. In R. Lerner (Ed.), Handbook of Child Psycholog: Vol. 1. Theoretical models of human development ( $6^{\text {th }}$ ed., pp. 210-257). Hoboken, NJ: Wiley.

Hoffman, L., Paris, S., \& Hall, E. (1994). Developmental psychology today ( $6^{\text {th }}$ ed.). New York: McGraw-Hill.

Lehr, U. (1999). Process of aging. The need for longitudinal, interdisciplinary cross-national research. Unpublished manuscript.

Lerner, R. (1984). On the nature of human plasticity. Cambridge, MA: Cambridge University Press.
Lerner, R. (1996). Relative plasticity, integration, temporality, and diversity in human development: A developmental contextual perspective about theory, process, and method. Developmental Psychology, 32(4), 781-786.

Lerner, R. (2002). Concepts and theories of human development ( $3^{\text {rd }}$ ed.). Mahwah, NJ: Erlbaum.

Lerner, R. (2006). Editor's introduction: Developmental science, developmental systems, and contemporary theories. In R. Lerner (Ed.), Handbook of Child Psychology: Vol. 1. Theoretical models of human development ( $6^{\text {th }}$ ed.). Hoboken, NJ: Wiley.

Lerner, R., \& Busch-Rossnagel, N. (1981). Individuals as producers of their development: Conceptual and empirical basis. In R. Lerner \& N. Busch-Rossnagel (Eds.), Individuals as producers of their development: A life-span perspective (pp. 136). New York: Academic Press.

Lerner, R., Easterbrooks, M., \& Mistry, J. (Eds.). (2003). Handbook of Psychology: Vol. 6. Developmental Psychology. New York: John Wiley \& Sons.

Lerner, R., \& Kauffman, M. (1985). The concept of development in contextualism. Developmental Review, 5, 309-333.

Lerner, R., \& Walls, T. (1999). Revisiting individuals as producers of their development. From dynamic interactionism to developmental systems. In J. Brandtstadter \& R. Lerner (Eds.), Action and self-development. Theory and research through the life span (pp. 3-36). Thousand Oaks, CA: Sage.

Magnusson, D. (Ed.). (1996). The life span development of individuals: Behavioral, neurobiological, and psychosocial perspectives. Cambridge, MA: Cambridge University Press.

Overton, W. (2003). Metatheoretical features of behaviour genetics and development. Human Development, 46, 356-361.

Overton, W. (2006). Developmental psychology: Philosophy, concepts, methodology. In R. Lerner (Ed.), Handbook of Child Psychology. Vol. 1: Theoretical models of human development $\left(6^{\text {th }}\right.$ ed., pp. 107-188). Hoboken, NJ: Wiley.

Rudinger, G, \& Rietz, C. (2001). Structural equation modeling in longitudinal research on aging. In J. Birren \& K.W. Schaie (Eds.), Handbook of the psychology of aging (5th ed.). San Diego, CA: Academic Press.

Rudinger, G., \& Thomae, H. (1990). The Bonn longitudinal study of aging. Coping, life adjustment, and life satisfaction. In P. Baltes \& M. Baltes (Eds.), Successful Aging: Perspectives from the behavioral sciences (pp. 265-295). New York: Cambridge University Press.

Schaie, K. W. (1983). Longitudinal studies of adult psychological development. New York: Guilford.

Schaie K. W. (1996). Intellectual development in adulthood: The Seattle Longitudinal Study. New York: Cambridge University Press.

Schaie, K. W., \& Hofer, S. (2001). Longitudinal studies in aging research. In J. Birren \& K.W. Schaie (Eds.), Handbook of the Psychology of Aging (5 ${ }^{\text {th }}$ ed., pp. 53-77). San Diego, CA: Academic Press.

Schroots, J., \& Birren, J. (1993). Theoretical issues and basic questions in the planning of longitudinal studies of health and aging. In J. Schroots (Ed.), Aging, health and competence: The next generation of longitudinal research. Amsterdam, Netherlands: Elsevier.

Vandenplas-Holper, C. (1998). Le développement psychologique a l'age adulte et pendant la vieillesse. Paris: Presses Universitaires de France.

Recebido: 2/05/2006 $1^{a}$ revisão: $15 / 09 / 2006$ Aceite final: 01/11/2006 